\title{
INVESTIGATIONS OF TEMPERATURES OF PHASE TRANSFORMATIONS OF LOW-ALLOYED REINFORCING STEEL WITHIN THE HEAT TREATMENT TEMPERATURE RANGE
}

\begin{abstract}
The paper presents the results of DSC analysis of steel B500SP produced in the process of continuous casting, which is intended for the production reinforcement rods with high ductility. Studies were carried out in the temperature range below $1000^{\circ} \mathrm{C}$ in a protective atmosphere of helium during samples heating program. The main objective of the study was to determine the temperature range of austenite structure formation during heating. As a result of performed experiments: $A c_{1 s}, A c_{1 f}-$ temperatures of the beginning and finish of the eutectoid transformation, $A c_{2}$ - Curie temperature of the ferrite magnetic transformation and the temperature $\mathrm{Ac}_{3}$ of transformation of proeutectoid ferrite into austenite were elaborated. Experimental determination of phase transformations temperatures of steel B500SP has great importance for production technology of reinforcement rods, because good mechanical properties of rods are formed by the special thermal treatment in Tempcore process.
\end{abstract}

Keywords: Thermal analysis, DSC, solid phase transformation, hypoeutectoid steel

\section{Introduction}

The analysis of steel phase transformation provides the necessary information needed for planning steel heat treatment technologies. The experimental methods suitable for the phase transformation analysis that are most frequently used in materials engineering and metallurgy are: dilatometry, differential thermal analysis (DTA) or differential scanning calorimetry (DSC) [1-3]. With the foregoing methods, complex analysis can be performed in order to determine: critical temperatures, enthalpy changes or analysis of the kinetics of steel phase transformations.

Temperatures accompanying metallurgical processes at present are attainable in laboratory conditions, which allows research on steels to be conducted within a very broad temperature range.

Examinations of steel phase transformations conducted at a high temperature range allow us to determine the characteristic temperatures - the solidus and the liquidus, which are both important for planning the continuous casting process technology [4-6]. Numerical simulation of metallurgical processes, at which the crucial physical phenomena like solidification extends in high temperature region, requires reliable information about latent heat of phase transformations and temperature dependence of the specific heat [7].

Within the temperature range below $1000^{\circ} \mathrm{C}$, which is typical for heat treatment operations, the process of formation of austenite structure is crucial. Controlling the course of the austenitic transformation allows us to consciously plan the mechanical parameters of products [8]. Recently developed quenching and tempering processes of reinforcement rods, such as Tempcore, may serve as an example. The correct selection of temperatures of subsequent stages of heat treatment operations is crucial to obtain the optimal combination of strength parameters and rebars ductility [9]. Another examples are new steel grades popular in the automotive industry, DP (Dual Phase) or TRIP (Transformation Induced Plasticity). During their production, the correct selection of the annealing temperature - which should be within the range of coexistence of ferrite and austenite is a vital process parameter [10].

The main objective of this study was to experimentally determine temperatures of phase transformations of low-alloyed hypoeutectoid steel $\mathrm{B} 500 \mathrm{SP}$, occurring within a temperature range below $1000^{\circ} \mathrm{C}$. The temperatures $A c_{1 s}-A c_{1 f}$ of the beginning and finish of the eutectoid transformation, the temperature $A c_{2}$ of the ferrite magnetic transformation and the temperature $A c_{3}$ of the end of transformation of proeutectoid ferrite into austenite were determined. The temperatures ware elaborated based on DSC experiments conducted at Netzsch STA F3 Jupiter analyser, for sample heating rate $10^{\circ} \mathrm{C} / \mathrm{min}$. Based on the obtained results, the influence of the sample mass on the temperature of phase transition was discussed. 


\section{Material characterisation}

\subsection{Low-alloyed reinforcing steel B500SP}

Steel B500SP, like other reinforcing steel grades, is continuously cast, and then rods for concrete reinforcement are manufactured by hot rolling. The parameter that distinguishes this steel grade from others is its enhanced ductility - the ability to achieve substantial deformations without a distinct increase in stress after exceeding the yield point. According to standard PN EN 1992-1-1:2005(U), two parameters have a decisive role in the reinforcing steel classification: $R_{m} / R_{e}$ - the ratio of tensile strength to the upper yield point and $A_{g t}$ - the percentage elongation recorded at the maximum force. The higher the values of these parameters, the steel ductility increases. Steel B500SP, in accordance with the presented classification, falls within the group of high ductility steels $\left(R_{m} / R_{e} 1.15 \div 1.35, A_{g t}\right.$ $\max 8 \%$ ) [11].

The optimal combination of mechanical properties and steel ductility can be obtained by special heat treatment after hot rolling process. The heat treatment operations consist of quenching and tempering of rods in order to obtain a structure comprising a layer of tempered martensite in the sub-surface zone and ferrite and pearlite in the axial zone of the rod [9].

The phase transformations are important in the reinforcing rods production process, and knowing their temperatures allows the individual stages of the heat treatment operation to be controlled.

\subsection{Samples}

The testing material was sampled from a cast strand after completion of the continuous casting process. Samples of steel were cut out in the shape of a cylinder with a diameter of $5 \mathrm{~mm}$ and a height of $1 \div 1.7 \mathrm{~mm}$ (Fig. 1a). The masses of the prepared samples were within the range of $149 \div 244 \mathrm{mg}$. The average chemical composition of the samples analysed, presented in Table 1, was determined with optical emission spectroscopy.

TABLE 1

The average chemical composition of analysed steel samples

\begin{tabular}{|c|c|c|c|c|c|c|c|c|c|}
\hline \hline \multicolumn{10}{|c|}{ Chemical composition [\%] } \\
\hline C & Mn & Si & P & S & Cu & Cr & Ni & Mo & Fe \\
\hline 0.22 & 0.79 & 0.17 & 0.02 & 0.003 & 0.23 & 0.08 & 0.08 & 0.01 & bal. \\
\hline
\end{tabular}

Before experiments, the samples were degreased with alcohol, and subsequently rinsed with distilled water and dried. The sample microstructure before the measurement was observed with a JCM-6000 NeoScope II scanning microscope.

The coarse-grained structure shown in Fig. 1b is a typical hypo-eutectoid steel structure after the continuous casting process, consisting of a mixture of ferrite and pearlite. a)

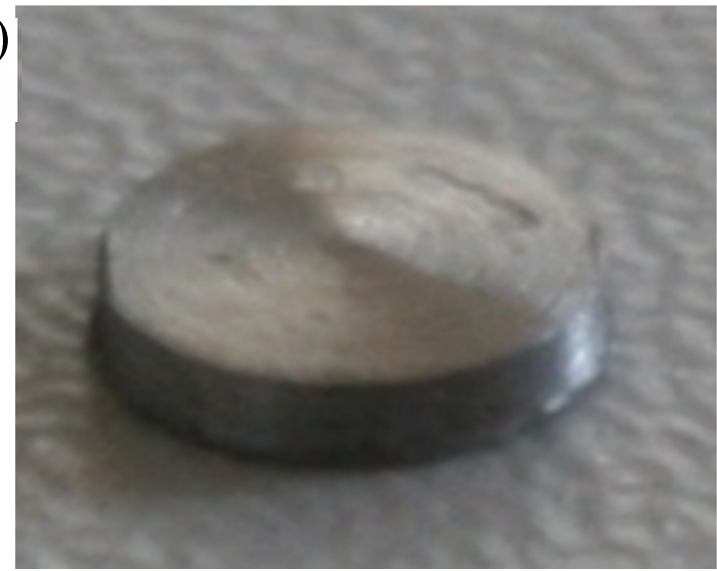

b)

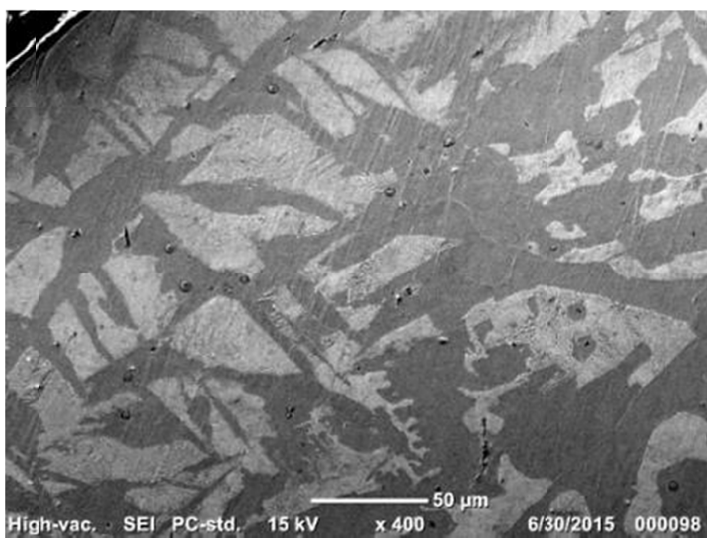

Fig. 1. a) A shape of the sample prepared for DSC measurements, b) coarse-grained structure of ferrite and perlite at top surface of sample

\section{Theoretical calculation of temperatures of phase transformations}

\subsection{Thermodynamic calculations in Fe-C pseudo binary system}

The temperature range of heat treatment operations is selected based on the phase transformation temperature which mostly depends on the carbon content in steel. In the case of multicomponent systems also other alloying elements should be taken in consideration because they have influence on the characteristic temperatures in the system [12].

Temperatures of phase transformations as well as phase diagrams can be determined using programs dedicated to thermodynamic calculations, which have recently become popular tools supporting research in the field of phase transformations [12-14]. FactSage is one of them. Along with the FSstel thermodynamic database, it allows the equilibrium transformation temperatures to be determined. Using FactSage, phase diagrams for the binary system $\mathrm{Fe}-\mathrm{C}$ and the pseudo binary multicomponent system (taking into account the constant content of $\mathrm{Mn}, \mathrm{Si}, \mathrm{Cu}$ and $\mathrm{Cr}$ ) were calculated. Constant amounts of alloying elements were set in calculation according to chemical composition presented in Table 1. Fig. 2 presents a comparison of the hypo-eutectoid area of the $\mathrm{Fe}-\mathrm{C}$ binary system (solid black line) and multicomponent pseudo binary system (dotted red line). 


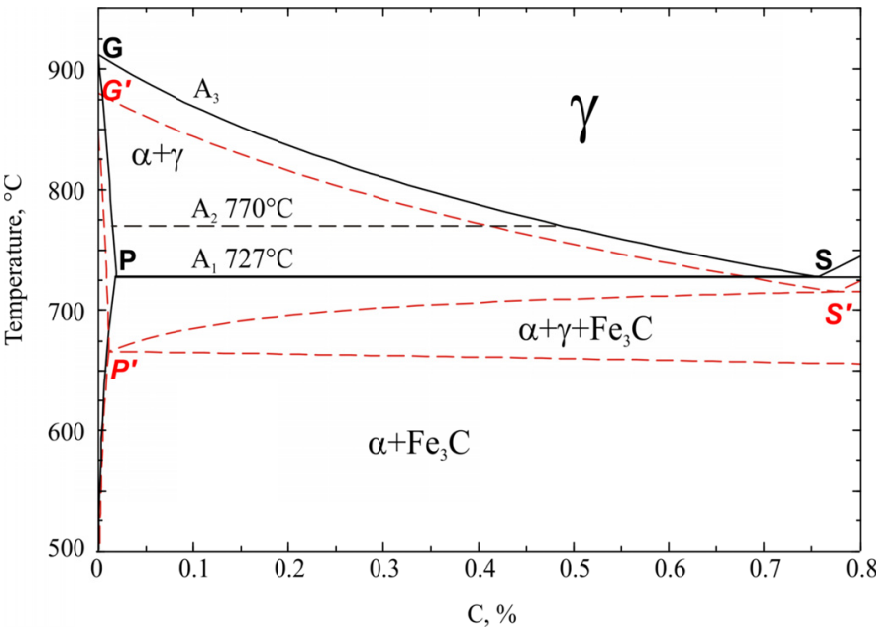

Fig. 2. The hypo-eutectoid region of the binary metastable $\mathrm{Fe}-\mathrm{C}$ diagram (black solid line) and multicomponent pseudo binary diagram, with constant amounts of: $\mathrm{Mn}, \mathrm{Si}, \mathrm{Cu}, \mathrm{Cr}$ (red dotted line)

On the basis of the presented comparison, one may determine the influence of alloying elements on the position of characteristic points and lines defining the areas of coexistence of individual phases.

In the $\mathrm{Fe}-\mathrm{C}$ binary diagram, two critical temperatures are crucial in heat treatment operations. The first one, denoted as $A_{1}$, is the temperature of eutectoid transformation of perlite (mixture of ferrite $\alpha$ and cementite $\mathrm{Fe}_{3} \mathrm{C}$ ) into austenite $\gamma$. In binary system this is invariant reaction taking place at constant temperature $727^{\circ} \mathrm{C}$. The second important temperature, denoted as $A_{3}$, is the temperature read from the GS line, at which during heating ferrite $\alpha$ completes its transformation into austenite $\gamma$.

The eutectoid reaction in steels, unlike the binary system, occurs within a certain temperature range denoted in literature as $A c_{1 s}$ (perlite-austenite transformation start temperature) and $A c_{1 f}$ (perlite dissolution finish temperature) [10]. In the pseudo binary system the diagram contains a hypo-eutectoid area comprising a mixture of three phases: ferrite $\alpha$, austenite $\gamma$ and cementite $\mathrm{Fe}_{3} \mathrm{C}$. The lines defining this area correspond to the temperatures of the beginning and the end of the transformation of perlite into austenite. Above the P'S' line a two phase region begins, which consists of a mixture of proeutectoid ferrite $\alpha$ and austenite $\gamma$. In this area, the temperature $770^{\circ} \mathrm{C}\left(A_{2}\right)$ of the ferrite magnetic transformation is marked with a dotted line. The temperature of the end of the transformation of ferrite into austenite in pseudo binary system is read from G'S' line. The presence of constant amount of $\mathrm{Mn}, \mathrm{Cu}$ and $\mathrm{Cr}$ in the system results in lowering temperature $\mathrm{A}_{3}$ compared with binary diagram. The effect of $\mathrm{Si}$ is the opposite - it causes an increase in the $\mathrm{A}_{3}$ temperature, but its impact in this case was reduced by the presence of a bigger amount of elements widening the austenite field ( $\mathrm{Mn}, \mathrm{Cu}, \mathrm{Cr}$ ).

Table 2 presents sequence and temperatures of individual phase transformations which were computed for the multicomponent pseudo binary system.
TABLE 2

The equilibrium temperatures of phase transformations computed in the FactSage 6.3 program for the system: $0.22 \% \mathrm{C}, 0.79 \% \mathrm{Mn}$, $0.17 \% \mathrm{Si}, 0.08 \% \mathrm{Cr}, 0.23 \% \mathrm{Cu}, \mathrm{Fe}$ bal.

\begin{tabular}{|c|c|l|}
\hline \hline $\mathbf{T},{ }^{\circ} \mathbf{C}$ & $\begin{array}{c}\text { Phase } \\
\text { transformation }\end{array}$ & \multicolumn{1}{c|}{ Description } \\
\hline 663.55 & $\alpha+\mathrm{Fe}_{3} \mathrm{C} \rightarrow \alpha+\gamma+\mathrm{Fe}_{3} \mathrm{C}$ & $\begin{array}{l}\text { the temperature of the beginning } \\
\text { of the euthectoid transformation } \\
\text { of perlite (mixture of ferrite and } \\
\text { cementite) into austenite }\end{array}$ \\
\hline 697.01 & $\alpha+\gamma+\mathrm{Fe}_{3} \mathrm{C} \rightarrow \alpha+\gamma$ & $\begin{array}{l}\text { the temperature of the end of the } \\
\text { transformation of perlite into } \\
\text { austenite }\end{array}$ \\
\hline 810.47 & $\alpha+\gamma \rightarrow \gamma$ & $\begin{array}{l}\text { the temperature of the end of } \\
\text { the transformation of ferrite into } \\
\text { austenite }\end{array}$ \\
\hline
\end{tabular}

Thermodynamic calculations in FactSage are based upon determining the equilibrium state between the phases for specific parameters of the state using Calphad method $[12,15]$. Calculations like these allow us quickly determine the characteristic temperatures of transformations for complex multicomponent systems. However, one should bear in mind that phase transformations during the heating operations runs at temperatures higher than the equilibrium which is connected with overheating of the sample. Obtained equilibrium temperatures cannot be directly compared with experimental results, since experiments are always conducted in non-equilibrium conditions with certain fixed heating rate [16].

\subsection{Empirical determination of phase transformation temperature}

The temperature range of the eutectoid transformation and the transformation of ferrite into austenite can be calculated on the basis of empirical formulas available in literature (multiple linear regression), taking into account the steel's chemical composition $[10,17]$.

$$
\begin{aligned}
A c_{1 s}= & 739-22.8 \mathrm{C}-6.8 \mathrm{Mn}+18.2 \mathrm{Si}+11.7 \mathrm{Cr}+ \\
& -15 \mathrm{Ni}-6.4 \mathrm{Mo}-5 \mathrm{~V}-28 \mathrm{Cu} \\
A c_{1 f}= & 752.7-11.2 \mathrm{C}-3.2 \mathrm{Mn}+33.2 \mathrm{Si}+25.9 \mathrm{Cr}+ \\
& -13.4 \mathrm{Ni}-36.8 \mathrm{Mo}-9.9 \mathrm{~V}+39.9 \mathrm{Cu} \\
A c_{3}= & 937.3-224.5 \sqrt{\mathrm{C}}-17 \mathrm{Mn}+34 \mathrm{Si}-14 \mathrm{Ni}+ \\
& +21.6 \mathrm{Mo}+41.8 \mathrm{~V}-20 \mathrm{Cu}
\end{aligned}
$$

The phase transformation temperatures calculated for steel B500SP on the basis of formulas $(1 \div 3)$ and chemical composition presented in Table 1 are: $A c_{1 s} 724.9^{\circ} \mathrm{C}, A c_{1 f} 764^{\circ} \mathrm{C}$, $A c_{3} 818.8^{\circ} \mathrm{C}$, respectively. 


\section{Experimental}

\subsection{Experimental equipment}

The experiments were conducted in the laboratory of thermal analysis of the Department of Ferrous Metallurgy, Faculty of Metals Engineering and Industrial Computer Science at AGH University of Science and Technology. A Netzsch STA 449 F3 Jupiter analyser with DSC carrier were used to register the temperatures of phase transformations in low temperature region (below $1000^{\circ} \mathrm{C}$ ). To ensure that the chemical composition of samples stays unchanged during experiments, research was carried out in inert atmosphere, with the simultaneous registration of sample mass (TG). Additionally, to control the measuring atmosphere, Evolved Gas Analysis (EGA analysis) of gases surrounding the sample during the measurement were performed by a quadrupole mass spectrometer Aëolos QMS 403, connected with STA furnace outlet by quartz heated capillary.

\subsection{Selection of experimental conditions}

The temperatures of phase transformation depends on the heating rate used in thermal analysis methods [6]. The importance of this parameter on shifts of the phase transformation temperature was presented at Fig. 3, where DSC curve registered for two different heating rates were compared.

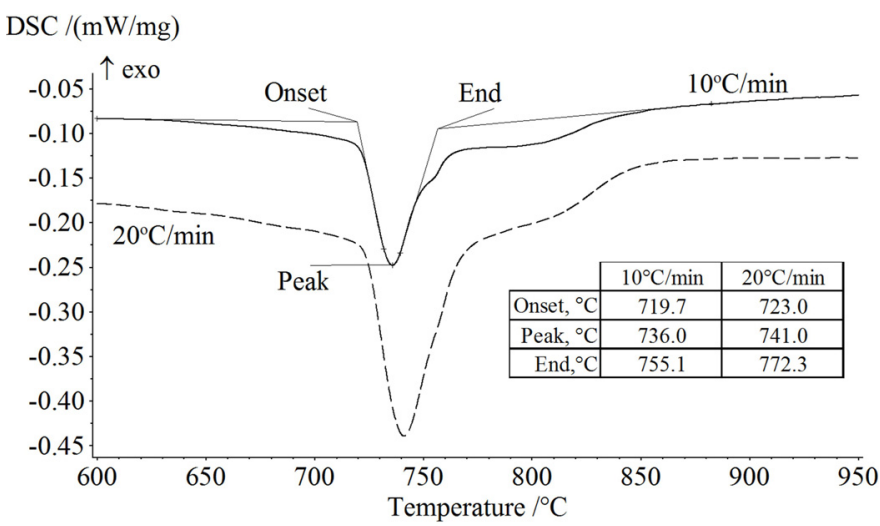

Fig. 3. The influence of heating rate on the temperatures of phase transformation of two samples with comparable masses $\left(10^{\circ} \mathrm{C} / \mathrm{min}-\right.$ $149 \mathrm{mg}, 20^{\circ} \mathrm{C} / \mathrm{min}-141 \mathrm{mg}$ )

The phase transformation temperatures, which are determined on the basis of characteristic measuring curve disturbances (Onset - extrapolated temperature of beginning of phase transformation, Peak - the maximum temperature of disturbances, Endset - extrapolated finish temperature of phase transformation), shift towards higher values with the heating rate increase. A more detailed research focused on heating rate could be found in literature [19]. In this paper effect of heating rate in aspects of samples decarburization was the main scope of preliminary test conducted with TG-DTA-EGA methods.
The application of low heating rates brings the system closer to the state of thermodynamic equilibrium, but it may involve decarburization of the samples. For low heating rates, the time of the sample exposure extends and the surface of the sample may undergo decarburization. This is also noticed by other authors [20-22].

Before performing the main DSC experiments, it was checked with the TG-DTA-EGA analysis, at which heating rates problems related to the decarburization of the samples may occur. During the preliminary tests, the DTA and the TG (sample mass changes) signals were recorded simultaneously. The atmosphere filling the measurement space of the sample was analysed during the test with quadrupole mass spectrometer (EGA analysis). To eliminate buoyancy effect, preliminary test were performed with baseline correction. Fig. 4 presents an example of TG-DTA curves supplemented by results of EGA analysis, registered during preliminary research with the $5^{\circ} \mathrm{C} / \mathrm{min}$ heating rate.

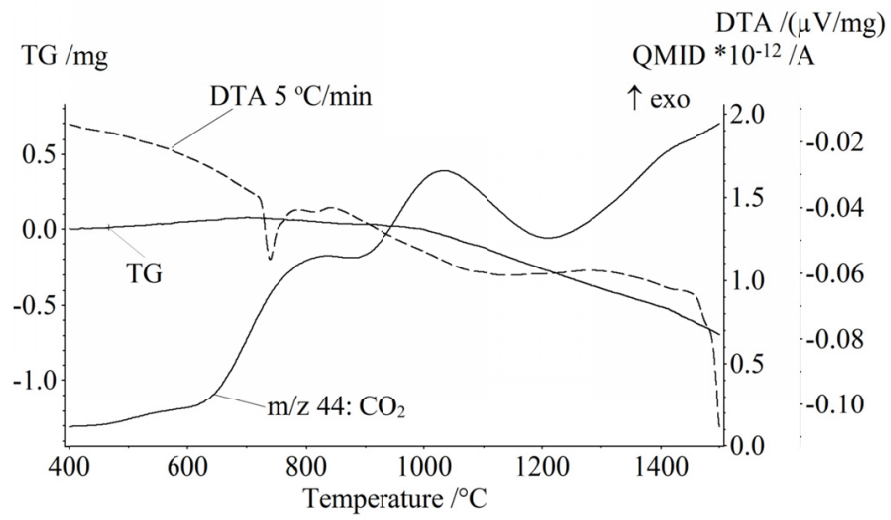

Fig. 4. Changes of sample mass caused by decarburization, registered during preliminary TG-DTA-EGA test with heating rate $5^{\circ} \mathrm{C} / \mathrm{min}$ in the atmosphere of helium (measurement with base line corrected)

Disturbances seen on the DTA curve in the form of endothermic peaks, are related to phase transformations of the analysed steel sample. Registered TG curve confirms that mass of the sample could decrease, especially at temperature above $1000^{\circ} \mathrm{C}$. The registered loss of sample mass, starting above $600^{\circ} \mathrm{C}$, is correlated with increases of intensity of ion current registered by spectrometer for carbon dioxide ions (with mas to charge ratio $\mathrm{m} / \mathrm{z} 44$ ). At low heating rates and with small quantity of oxygen present in the system, steel samples may undergo a decarburization and carbon dioxide evolved during experiments is confirmation of this phenomena.

It should be noted that decarburization of samples must not be a part of all experiments carried out with low heating rates, and steel samples with higher carbon content are more prone to decarburization.

As a results of preliminary test, heating rate of $10^{\circ} \mathrm{C} / \mathrm{min}$ was identified as an optimal experimental conditions at which masses of analysed samples stay unchanged.

Differential Scanning Calorimetry method was used in the main part of investigations because the accuracy of DSC is 
higher than DTA method. Prepared samples were heated to a temperature of $40^{\circ} \mathrm{C}$ to $1000^{\circ} \mathrm{C}$ at a rate of $10^{\circ} \mathrm{C} / \mathrm{min}$, in a helium atmosphere with gas flow rate set at $50 \mathrm{ml} / \mathrm{min}$. The samples were analysed in corundum crucibles. In all cases the reference crucible remained empty. No changes in the sample mass or spectrometer indications were recorded, that could confirm the decarburization of the samples during DSC experiments.

Before performing main DSC experiments, temperature calibration of the instrument was carried out using set of standard materials (In, Sn, Zn, Al, Ag, Au) with known melting temperatures.

\section{Results and discussion}

\subsection{Results of DSC analysis}

Obtained results were repeatable, almost identical DSC curves were obtained for all investigated samples. In all cases, registered phase transformations was manifested on DSC curve as a group of connected endothermic peaks. The combined nature of the peaks hampers the precise determination of the temperatures of individual phase transformations. The use of a second derivative of the DSC signal, which more clearly presents the beginning and the end of individual disturbances, solved the problem of analysis of superimposing peaks. Fig. 5 presents the DSC curve and the D2DSC graph of the second derivative of the DSC signal recorded for one of the samples analysed. The results were restricted to temperature range $600 \div 950^{\circ} \mathrm{C}$ because no effects related to phase transformations under $600^{\circ} \mathrm{C}$ were recorded.

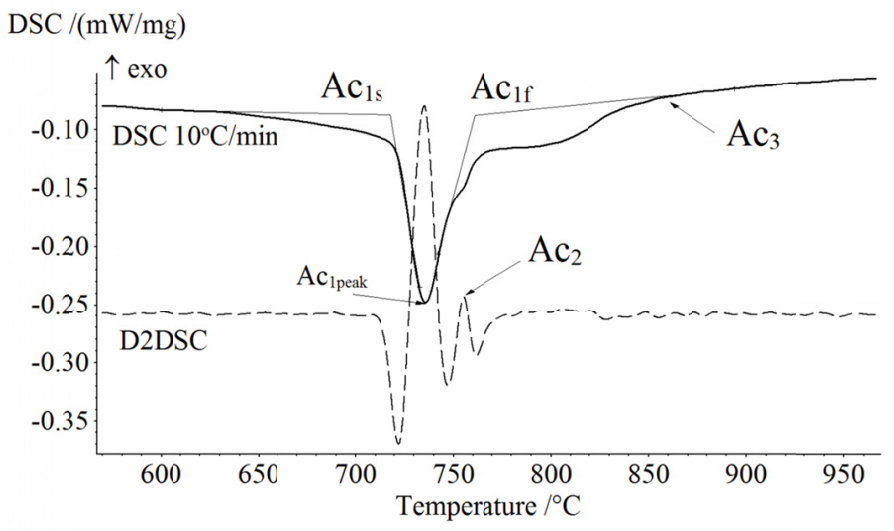

Fig. 5. The DSC curve and the second derivative of the DSC signal (D2DSC), recorded during heating at a rate of $10^{\circ} \mathrm{C} / \mathrm{min}$

The temperature $A c_{1 s}$, of the beginning of the eutectoid reaction was determined as the Onset (extrapolated beginning of a disturbance) of the first endothermic peak visible on the DSC curve. The disturbance related to the beginning of austenite precipitation runs slowly in a fairly wide temperature range, which is related to the structure of the prepared sample (Fig. 2b).
The rate of transformation of pearlite into austenite depends on the initial grain size and the dispersion of cementite, dissolving during this stage of transformation. The temperatures $A c_{1 s}$ for the all samples under investigation was determined within the range of $719 \div 721^{\circ} \mathrm{C}$.

The disturbance related to the transformation of pearlite into austenite reaches its maximum at temperature denoted in Fig. 5 as $A c_{1 \text { peak }}$. At this temperature, the sample structure corresponds to an area consisting of three phases: ferrite, austenite and undissolved cementite. After exceeding the $A c_{1 \text { peak }}$ temperature, the DSC signal reverts to the base line. The temperature of the end of transformation of pearlite into austenite $A c_{1 f}$, was defined as the Endset (extrapolated finish of a disturbance) of the analysed peak. For the samples under investigation, the $A c_{1 f}$ temperature was determined within the range of $755 \div 763^{\circ} \mathrm{C}$.

During this stage, a small disturbance appears on the DSC curve, seen as a small deviation of the DSC curve towards the right. This disturbance is related to the magnetic transformation of ferrite. Because of the location of the peak, the temperature of ferrite Curie temperature cannot be precisely evaluated at DSC curve. The second derivative curve was used for analysis of this disturbance. The Curie $A c_{2}$ temperature was determined as the temperature of the second peak that was pointing up on the D2DSC curve. In the group of analysed samples temperature of ferrite Curie transformation was determined in the range $755 \div 757^{\circ} \mathrm{C}$.

The next broad endothermic disturbance, starting straight after the magnetic transformation, was identified as the transformation of proeutectoid ferrite into austenite. The determination of the temperature of transformation beginning is not unambiguous. In order to determine the temperature of the disturbance beginning, a DSC curve deconvolution is required, which can be carried out with one of the methods of separation of combined peaks proposed by B. Pawłowski [18]. In the presented investigations the temperature of the end of the disturbance was determined. The temperature $A c_{3}$ of the end of the transformation of proeutectoid ferrite into austenite for the samples under investigation was evaluated in the range of $843 \div 850^{\circ} \mathrm{C}$.

\subsection{Discussion of obtained results}

Obtained temperatures of phase transformations were elaborated on the base of four steel samples with different masses. The masses of the investigated samples, was in the range of $149 \div 244 \mathrm{mg}$. Table 3 presents the elaborated temperatures of phase transformations for all investigated samples obtained as a result of the DSC heating experiments in the range below $1000^{\circ} \mathrm{C}$.

Based on the obtained results, the influence of the sample mass on the temperature of phase transformations was discussed. The comparison of results obtained for samples no. 1 and 4 (with lowest and highest mass), was presented in Fig. 6 as an example of obtained trend in shifts of characteristic DSC curve disturbance for analysed samples. 
TABLE 3

The temperatures of phase transformations of steel B500SP within the temperature range below $1000^{\circ} \mathrm{C}$, recorded during samples heating $10^{\circ} \mathrm{C} / \mathrm{min}$

\begin{tabular}{|c|c|c|c|c|c|}
\hline \hline $\begin{array}{c}\text { Samples } \\
\text { No. }\end{array}$ & $\begin{array}{c}\text { Mass, } \\
\mathbf{~ m g}\end{array}$ & $\begin{array}{c}\mathbf{A} \boldsymbol{c}_{\mathbf{1 s}}, \\
{ }^{\circ} \mathbf{C}\end{array}$ & $\begin{array}{c}\mathbf{A} \boldsymbol{c}_{2}, \\
{ }^{\circ} \mathbf{C}\end{array}$ & $\begin{array}{c}\mathbf{A} \boldsymbol{c}_{\mathbf{1}}, \\
{ }^{\circ} \mathbf{C}\end{array}$ & $\begin{array}{c}\mathbf{A} \boldsymbol{c}_{\mathbf{3}}, \\
{ }^{\circ} \mathbf{C}\end{array}$ \\
\hline $\mathbf{1}$ & 149 & 719.7 & 755.3 & 755.1 & 843.2 \\
\hline $\mathbf{2}$ & 159 & 720.8 & 755.7 & 757.6 & 842.1 \\
\hline $\mathbf{3}$ & 175 & 720.6 & 756.3 & 757.2 & 846.1 \\
\hline $\mathbf{4}$ & 244 & 721.0 & 756.8 & 763.0 & 850.3 \\
\hline
\end{tabular}

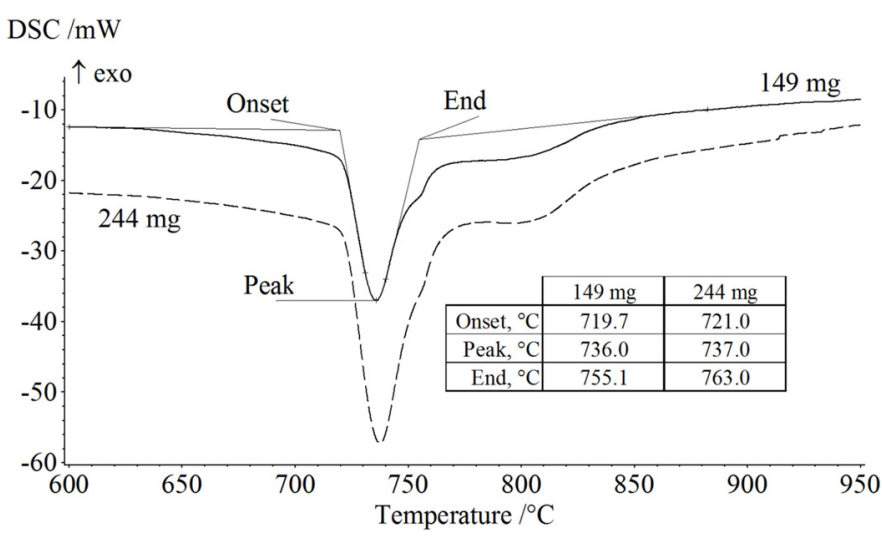

Fig. 6. The influence of samples mass on the temperatures of phase transformation registered during DSC experiments with the same heating rate $10^{\circ} \mathrm{C} / \mathrm{min}$

The biggest influence of sample mass on shifting the temperature of phase transformations was registered in case of $A c_{1 f}$ and $A c_{3}$ temperatures, obtained as the Endset of the disturbance at DSC curve. The finish temperature of eutectoid transformation was shifted to higher temperatures with increasing mass of the samples. The biggest difference in $A c_{1 f}$ temperature, about $8^{\circ} \mathrm{C}$, was registered for the samples no. 1 and 4 , where difference in samples masses was $95 \mathrm{mg}$. A similar dependence was observed in the case of $A c_{3}$ temperature of the finish of ferrite to austenite transformations. Shifting the temperature of the end of phase transformations to the higher temperature region could be explained by the fact that more time is required to complete phase transformation in whole volume of the larger sample.

In case of temperature $A c_{1 s}$, hardly noticeable differences in evaluated temperatures was registered. The temperatures of the beginning of eutectoid transformations was almost the same for all investigated samples. The Onset temperatures of phase transformations is not disturbed by samples mass in DSC, DTA methods.

The temperature $A c_{2}$ of magnetic transformations of ferrite, evaluated as the Peak temperature (at second derivative curve of DSC signal) did not differ much in group of analysed samples. Usually, in DSC measurements, the Peak temperature of disturbance is not representative value, because it is affected by the mass of the sample. This kind of dependency was not clearly obtained at performed experiments, which was prob- ably caused by too small diversification of the sample masses. Lack of significant differences in the peak temperatures, was also the result of heating rate used in the experiments. In case of higher heating rates, the temperature gradient in the larger samples increase, and the differences in Peak temperatures are more distinguished.

The temperature of the beginning $\left(A c_{1 s}\right)$ and the end $\left(A c_{1 f}\right)$ of the eutectoid transformation calculated with the formulas $(1 \div 2)$, as well as the published by P. Bała [9], fairly well coincide with the findings presented at this paper. Temperature $A c_{2}$, determined within the range of $755.3 \div 756.8^{\circ} \mathrm{C}$, corresponds with the data presented in literature [7].

The $A c_{3}$ temperature of the end of the transformation of ferrite into austenite, for each of the samples, was much higher than calculated with equation (3), which results from the heating rate applied in the examinations. Similar temperature of the ferrite to austenite finish temperature was found in literature [9].

\section{Conclusions}

The heat treatment operations of steel B500SP, performed after hot rolling, consist of quenching and tempering the rods in order to obtain optimal combination of mechanical properties and ductility. Controlling individual stages of hot rolling as well as Tempcore process requires knowledge of the critical temperatures of phase transformations.

The temperatures of phase transformations for low-alloyed, hypo-eutectoid steel B500SP in the temperature range of heat treatment operations (below $1000^{\circ} \mathrm{C}$ ) was obtained in DSC experiments performed with heating rate $10^{\circ} \mathrm{C} / \mathrm{min}$.

During heating operations austenite structure starts to precipitate from pearlite at temperature $A c_{1 s}$. The average value for temperature of the beginning of austenite structure formation for investigated steel was $720.5^{\circ} \mathrm{C}$.

The transformation of perlite ends at $A c_{1 f}$ temperature. In the group of samples analysed the average value for the end of perlite dissolution process was $757.4^{\circ} \mathrm{C}$.

In the same temperature range magnetic transition of ferrite was registered as a small deviation of DSC signal. The location of this disorder made it impossible to obtain the $A c_{2}$ temperature at DSC curve. Second derivative curve of the DSC signal was used. The average value of the Curie temperature for the samples analysed, read as a peak on the curve of the second derivative of the DSC signal, was $756^{\circ} \mathrm{C}$.

Further heating activates transformation of proeutectoid ferrite into austenite. The start temperature was not elaborated due to superimposing peaks at DSC curve. The $A c_{3}$ finish temperature of transformation of ferrite into austenite, calculated as an average value in the group of investigated samples was $845.1^{\circ} \mathrm{C}$.

The paper presents discussion concerning the mass of the analysed samples as a parameter disturbing obtained results. In case of investigated samples finish temperature of phase transformations $\left(A c_{1 f}\right.$ and $A c_{3}$ ) was slightly affected by mass of the samples. Other temperatures of phase transformations were 
unaffected by this factor. In performed DSC experiments more important parameter was heating rate and its proper selection at which no decarburization of the samples were registered.

It must be noted that due to the applied heating rate the transformation temperatures obtained in the DSC experiments should be treated as the upper limit of estimation of their corresponding equilibrium temperatures. In all cases the resulting temperatures are higher compared to the equilibrium temperature calculated for pseudo binary system in FactSage programme. In case of heat treatment processes which proceeds in no equilibrium conditions, the information about temperatures of phase transformation obtained experimentally should be more useful.

\section{Acknowledgements}

Author kindly acknowledge the company JEOL (EUROPE) SA branch in Poland for allowing access to the JEOL electron microscope JCM-6000 NeoScope II for this investigation.

This research was supported through the statutory founds of the AGH UST, as part of the Project No. 11.11.110.293.

\section{REFERENCES}

[1] R. Dziurka, J. Pacyna, Arch. Metall. Mater. 57, 943-950 (2012).

[2] B. Pawłowski, Arch. Metall. Mater. 57, 957-962 (2012).

[3] M. Gojić, M. Sućeska, M. Rajić, J. Therm. Anal. Calorim. 75, 947-956 (2004).

[4] A. Kalup, B. Smetana, M. Kawuloková, et al., J. Therm. Anal. Calorim. 127, 123-128 (2017).

[5] I. Sohn, R. Dippenaar, Metall. Mater. Trans. B 47, 2083-2094 (2016).
[6] E. Wielgosz, T. Kargul, J. Therm. Anal. Calorim. 119, 1547-1553 (2015).

[7] T. Kargul, E. Wielgosz et al., Arch. Metall. Mater. 60, 121-125 (2015).

[8] M. Kawuloková, B. Smetana, S. Zlá, et al., J. Therm. Anal. Calorim. 127, 423-429 (2017).

[9] P. Bała, Arch. Metall. Mater. 54, 1223-1230 (2009).

[10] B. Pawłowski, Journal of Achievements in Materials and Manufacturing Engineering 49, 331-337 (2011).

[11] M. Lisowska, Nowoczesne Budownictwo Inżynieryjne 3, 74 (2008).

[12] P. Presoly, R. Pierer, C. Bernhard, Metall. Mater. Trans. A 44, 5377-5388 (2013).

[13] E. Wielgosz, T. Kargul, J. Falkus, Comparison of experimental and numerically calculated thermal properties of steels. In: Proceedings paper, METAL 2014: 23rd International Conference on Metallurgy and Materials, Brno, Czech Republic, 2014.

[14] A. Grajcar, W. Zalecki, W. Burian, Metals 6 248, 2-14 (2016).

[15] T. Kargul, J. Falkus, Steel Res. Int. 81, 953-958 (2010).

[16] B. Smetana, S. Zlá, J. Dobrovska, et al., Int. J. Mater. Res. 101, 398-404 (2010).

[17] J. Trzaska, L.A. Dobrzański, J. Mater. Process. Tech. 192-193, 504-510 (2007).

[18] B. Pawłowski, Journal of Achievements in Materials and Manufacturing Engineering 54, 185-193 (2012).

[19] M. Žaludová, B. Smetana, S. Zlá, et al., Influence of experimental conditions on data obtained by thermal analysis methods. In: Proceedings paper, METAL 2013, Brno, Czech Republic, 2013.

[20] S. Raju, B.J. Ganesh, A. Banerjee, E. Mohandas, Materials Science and Engineering A 465, 29-37 (2007).

[21] B. Smetana, M. Žaludová, M. Tkadlečková, et al., J. Therm. Anal. Calorim. 112, 473-480 (2013).

[22] G.P. Krielaart, C.M. Brakman, S. Van Der Zwaag, Journal of Materials Science 31, 1501-1508 (1996). 